\title{
An unusual case of myocardial infarction
}

\section{Un caso insolito di infarto miocardico}

\author{
Riccardo Rovetta, Enrico Vizzardi, Antonio D’Aloia, Ivano Bonadei, \\ Edoardo Sciatti, Marco Metra
}

\begin{abstract}
An unusual case of myocardial infarction. R. Rovetta, E. Vizzardi, A. D'Aloia, I. Bonadei, E. Sciatti, M. Metra. Myocardial infarction may be the result of embolism of calcified material from the aortic valve or thrombotic formations adhering to the same. We report a case of late myocardial infarction secondary to embolization from a
\end{abstract}

\begin{abstract}
thrombus adherent to the aortic valve jutting out in the ostium of the left main coronary artery.

Keywords: Myocardial infarction, thrombotic embolization, echocardiography.
\end{abstract}

Monaldi Arch Chest Dis 2014; 82: 110-111.

Department of medical and surgical, radiological sciences and public health specialties. University of Study of Brescia.

Corresponding author: Riccardo Rovetta; Piazzale Spedali civili, 1; 25100 Brescia, Italy; Tel: +39 030 3995575; Fax: +39 0303995018 ; E-mail address:rovetz85@yahoo.it

Myocardial infarction is the evidence of myocardial necrosis in a clinical setting consistent with acute myocardial ischemia [1]. In particular, myocardial injury can be related to primary myocardial ischemia, such as plaque rupture and/or intraluminal coronary artery thrombus formation, or to supply/demand imbalance of myocardial ischemia, such as coronary spasm, coronary embolism or vasculitis, aortic dissection etc [1].

Regarding this second aspect, we hereby report the case of a 66 years old man admitted to the Intensive Coronary Care Unit for late myocardial infarction. The patient presented without chest pain but ST-segment elevation and Q waves in the infero-lateral derivations at 12-lead electrocardiogram (Figure 1), with a concomitant increase of myocardial necrosis markers (Troponin I max value $10.8 \mathrm{ng} / \mathrm{mL}$ ). Acutely the patient was treated with double antiplatelet therapy (aspirin plus clopidogrel), infusion of nitrate, heparin and statin.

Considering the history of bicuspid aortic valve, the patient underwent 2D and 3D-transoesophageal echocardiography evaluation that confirmed the valve malformation without critical stenosis and showed the presence of a hypoechogenic formation jutting out in the ostium of the left main coronary

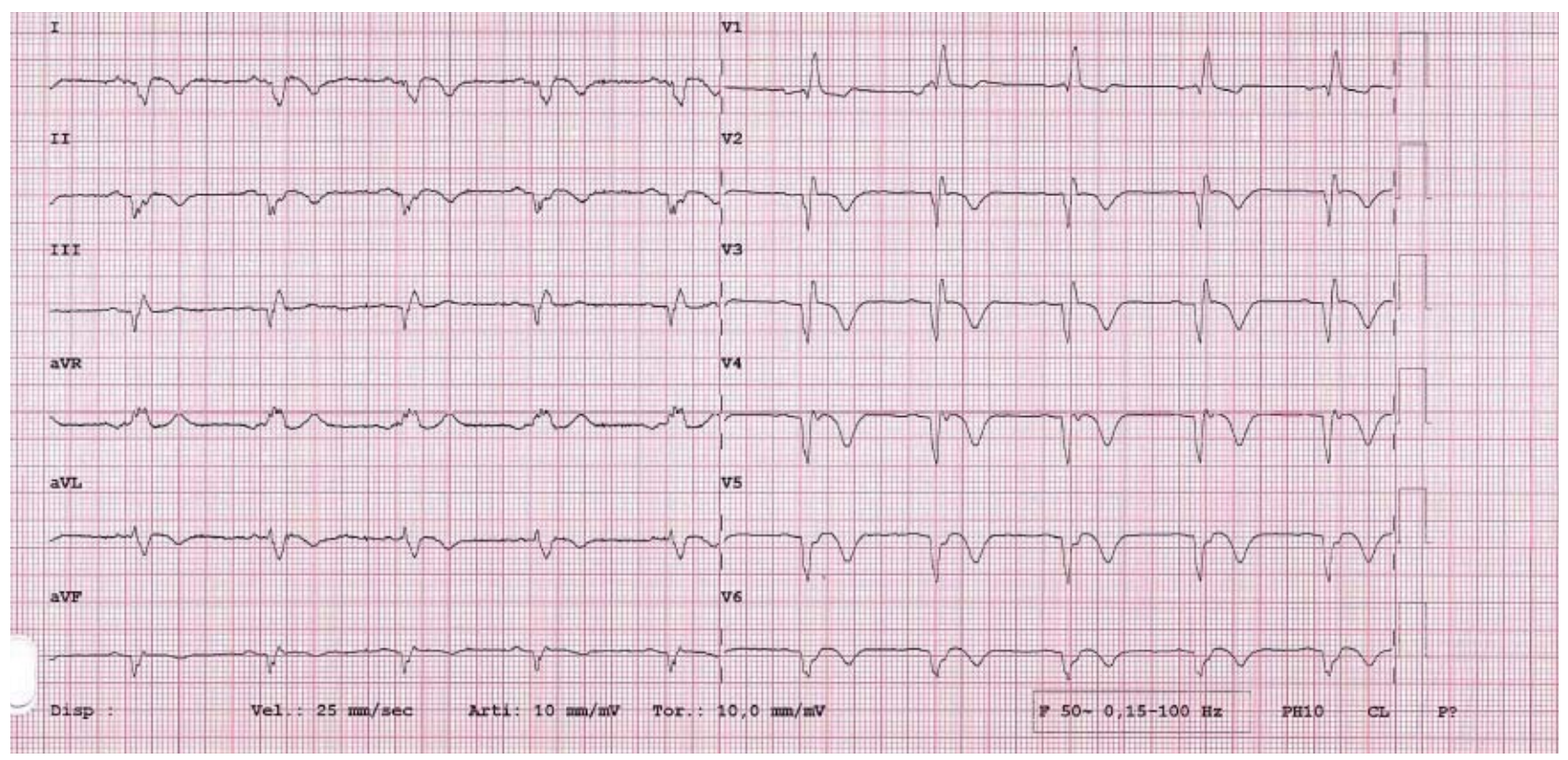

Figure 1. - 12-lead ECG: ST-segment elevation and Q waves in the infero-lateral derivations. 


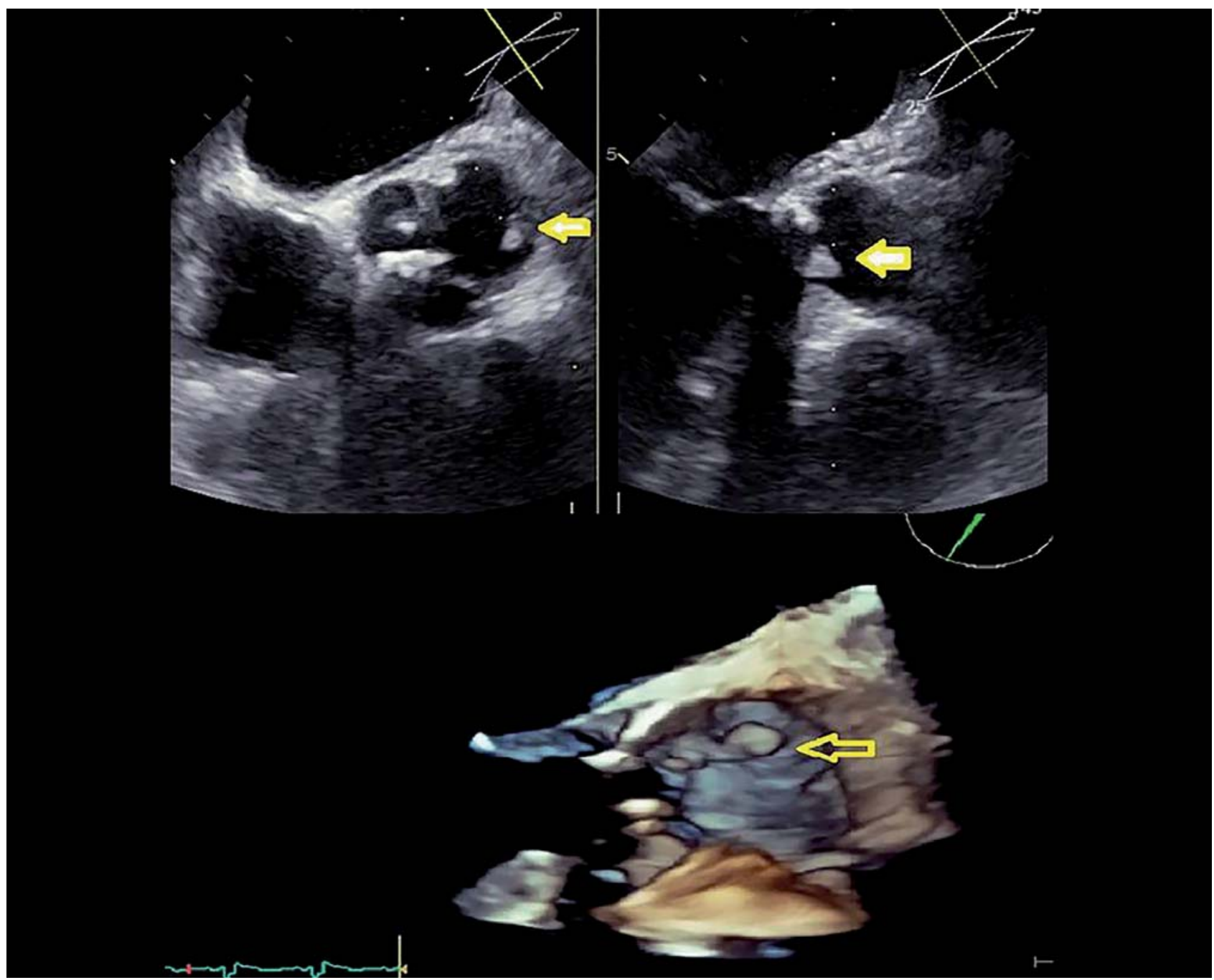

Figure 2. - 2D (top) and 3D (bottom) transesophageal echocardiography pictures showing the presence of a hypoechogenic formation jutting out in the ostium of the left main coronary artery.

artery (Figure 2). The presence of infective endocarditis had been excluded for the negativity of the Modified Duke's Criteria. Cardiac computed tomography showed the thrombotic nature of the lesion with probably distal embolization which may explain the myocardial infarction; the main coronary arteries were free from thrombotic formations. Hypercoagulability tests were found negative and the patient did not smoke. After two weeks of heparin infusion the transesophageal echocardiography showed the complete resolution of the thrombotic formation.

In Literature some cases are reported dealing with acute myocardial infarction in patients with bicuspid aortic valve due to embolization of calcific material from the valve. This occur during catheterization or alternatively may be spontaneous [2-3]. Only in one case a thrombotic coronary embolization is reported in a patient with mitral and aortic mechanical prostheses with an incorrect International Normalized Ratio (INR) level, associated with pulmonary embolism [4].

In our case it is possible that the thrombus on the valve was responsible of the myocardial infarc- tion by means of micro-embolism of parts of this. This situation may have been easier due to the contiguity with the left main coronary.

\section{References}

1. Thygesen K, Alpert JS, Jaffe AS, et al. Writing Group on the Joint ESC/ACCF/AHA/WHF Task Force for the Universal Definition of Myocardial Infarction; SC Committee for Practice Guidelines (CPG). Third universal definition of myocardial infarction. Eur Heart J 2012; 33(20): 2551-67.

2. Dauvergne C, Araya M, Valenzuela J, et al. Acute myocardial infarction after left-heart catheterization in a patient with severe calcified bicuspid aortic stenosis. JACC Cardiovasc Interv 2014; 7(2): e5-6.

3. Guy JM, Lamaud M, Favre JP, et al. Spontaneous calcified coronary embolism and myocardial infarction. Apropos of a case. Arch Mal Coeur Vaiss 1991; 84(12): 1865-7. [Article in French].

4. Protasiewicz M, Rojek A, Gajek J, et al. Cardiac arrest due to left circumflex coronary artery embolism as a complication of subtherapeutic oral anticoagulation in a patient with mitral and aortic mechanical valve prostheses. Postepy Kardiol Interwencyjnej 2013; 9(1): 97-100. 